\title{
A CULTURA DA MARCA E SEUS REFLEXOS NO DIREITO DO CONSUMIDOR
}

\author{
Josinaldo Leal de Oliveira ${ }^{1}$ \\ Thyago Cezar ${ }^{2}$
}

\section{RESUMO}

A cultura da marca tem introduzido a possibilidade de grandes discussões a respeito da necessidade de proteção efetiva dos consumidores. A cultura da marca tem sido capaz de ditar condutas e modos de viver dos consumidores em sociedade e isso não pode ficar a margem das reflexões dos consumeristas, na medida em que consumidores muitas vezes estão expostos a um modelo de mercado nocivo. O Direito do consumidor ainda tem muito que contribuir para que possamos alcançar um mercado de consumo harmonioso e equilibrado, daí a necessidade do estudo da cultura da marca e seus reflexos no direito do consumidor.

Palavras-chave: Marca; Cultura da marca; Consumidor; Defesa do consumidor; Sociedade.

\section{THE CULTURE OF THE BRAND AND ITS REFLEXES IN THE RIGHT OF THE CONSUMER}

\begin{abstract}
The culture of the mark has been introducing the possibility of great discussions as to the necessity of effective protection of the consumers. The culture of the mark has been able to dictate conducts and ways of living on the consumers in society and that cannot be the edge of the reflections of the consumers. The Right of consumer still has much that to contribute so that we can reach a market of harmonious and balanced consumption, from there the necessity of the study of the culture of the mark and his reflexes in the right of the consumer.
\end{abstract}

Keywords: Brand; Brand culture; Consumer; Consumer defense; Society

\section{INTRODUÇÃO}

O presente trabalho deseja apresentar aos operadores do Direito, tema que é originário das ciências da Comunicação e Sociologia, que tem extrema importância e influencia no mercado de consumo e nos consumidores.

Como isso, nos aventuraremos a buscar perspectivas que fujam das que são comumente abordadas, visando trazer um olhar sob um prisma que seja incomum aos debates que são margeados com frequência pelas diretrizes do Código de Defesa do Consumidor. Utilizamos o termo aventurar, pois há a necessidade de que fique demonstrado o ingresso em

\footnotetext{
${ }^{1}$ Advogado, Doutor em Ciências Jurídicas e Sociais, Pós Graduado em Direito Civil, Direito do Consumidor e Docencia do ensino Superior.

${ }^{2}$ Possui graduação em Direito pelo Instituição Toledo de Ensino(2010) e especialização em Direito Processual Civil pela Universidade Anhanguera - Uniderp(2013). Tem experiência na área de Ciência Política.
} 
mares não, ou muito pouco frequentados pelos operadores do Direito, alertando para isso, a grande dificuldade de sua abordagem.

Visamos apresentar uma breve análise a respeito da Cultura de Marcas, ou "Brand Culture", temática que tem recebido pouquíssima abordagem pelos estudos voltados à Defesa do Consumidor, visto que sob o olhar atual da legalidade, não há um aparente ferimento aos direitos já positivados.

Entretanto, há de se verificar que a Cultura das Marcas, pode provocar problemas de cunho social, criando estigmas visíveis no seio da sociedade moderna. É necessário lembrar que além destes estigmas, há flagrante ataque à cultura regional, criando entraves à construção da identidade do povo.

Muito embora, ainda que o tema não afete diretamente os direitos já positivados, pode interferir os direitos não tangíveis da sociedade, podendo fomentar uma divisão invisível de "castas" na sociedade, onde parte da sociedade adotam uma ou outra marca.

Sendo imperioso ressaltar que as marcas, sejam elas quais forem, servem inicialmente para identificar um produto, ou serviço, de mesma origem ou não, mas podem chegar ao ponto de diferenciar quem são seus consumidores.

Por ser uma Ciência Social, o Direito, principalmente nas cadeiras do Direito do Consumidor, não pode se furtar de trazer à comunidade o interesse e a luta para construção, manutenção da identidade popular que pode facilmente sofrer mutações por conta do avantajado ataque do mercado de consumo com suas mais variadas técnicas de vendas.

Apoiando-nos nestes argumentos, desejamos provocar o debate, alertando a comunidade jurídica para a necessidade de voltar maiores atenções aos temas pouco ou raramente frequentados pelos operadores do Direito. De tal modo, não há pretensão de exaurir o tema, mas tão somente iniciar possibilidades para seu debate e análise.

Neste ponto, desejamos chamar a atenção dos estudiosos à Cultura das Marcas e seu ataque frontal aos consumidores.

Para desenvolver este trabalho, utilizaremos referenciais teóricos, como livros, artigos, periódicos, dentre outros materiais que se fizerem necessários à produção.

\section{A MARCA}

Sempre existiram várias formas de promoção de mercadorias, em tempos antigos, muito antes da marca adquirir seu significado moderno, tinha-se como costume indicar qual 
era a proveniência do produto agrícola ou manufaturado, sendo a marca para atestar a excelência ou prestígio do produto.

Nos dias atuais, praticamente tudo que se vê, come ou veste, se usa, fala, tem a presença das marcas, sejam elas mais famosas, muito conhecidas, ou outras de menor expressão. Devido a isso, compreende-se o motivo das marcas fazerem parte significante dos estudos e investimentos de marketing das instituições.

As marcas reinventaram as relações tradicionais, criando um domínio sobre tudo que pode ser feito, fornecido ou esperado. Desta forma, produtos locais adquiriram renome local, regional nacional e internacional, sendo fontes que geram prestígio e renda.

Conceitua-se marca como um desenho, símbolo, signos, ou combinações desses elementos que tem característica de identificar bens e, ou serviços de um fornecedor, diferenciando-os. É uma promessa da empresa em fornecer uma variedade específica de atributos, benefícios uniformes aos compradores.

Ressalta-se que em inglês, marca significa brand, que deriva da palavra nórdica antiga brandr, que significa queimar, já que naquela época os proprietários de gados, usavam fogo para marcar e identificar os animais que eram provenientes de suas criações.

Não há como precisar quando surgiu a primeira marca, contudo, pode-se assumir que sua existência não é recente, havendo muitos indícios de seu surgimento nos tempos antigos. (ALMEIDA, 2010, p.21)

$\mathrm{Na}$ Grécia, os navios com cargas especiais eram anunciados a viva voz, já em Roma, anunciavam por mensagens escritas os endereços onde eram vendidos calçados e vinhos, ou ainda, onde poderiam encontrar um escriba.

Para imensa maioria da população analfabeta, pinturas eram o caminho adequado para identificar os comerciantes e suas mercadorias.

Já na idade média, as chamadas trademarks, ou seja, marcas de comercio, passaram a integrar as medidas para ajustar a produção e comercialização dos bens que seriam destinados às demandas do mercado. Constituíam ainda uma proteção para quem fosse realizar as compras dos produtos, visto que este poderia se resguardar da má qualidade dos produtos, constatação que era comum àquela época.

Conta-se que muitos artesãos, tecelões e ourives, franceses, italianos, ingleses eram obrigados a ter suas próprias marcas para que as corporações tivessem a possibilidade de preservar o monopólio, trazendo identificações às falsificações, ou aqueles produtores, cuja 
produção estivessem em desacordo com as especificações técnicas e de qualidade da agremiação a qual fazia parte.

Dando um salto gigante na história, temos que no século XX, muitas marcas lançadas pela indústria tiveram um grande sucesso, visto que foram divulgadas imensamente pela publicidade da época.

Em 1929, com a crise econômica, as marcas serviram como forte apoio para a grande concorrência de preços. Deixando um relevante aprendizado, onde em tempos de crise, a publicidade comercial não deve ser deixada de lado, mas sim ampliada, sob pena de trazer à empresa seu fechamento. (PINHO, 1996, p.1-13)

Para cumprir sua principal função, tem-se como característica de destaque que a marca deve distinguir um produto ou serviço no mercado. Importa salientar que a marca não deve ter a mesma identificação pelo nome comum ao qual o produto ou serviço é conhecido.

A diferenciação semântica da marca e o produto ou serviço identificado, não se limita à essa valoração abstrata, podendo ter contornos de maior complexidade e dinamismo, observando-se o caso concreto.

Nomes de domínio, títulos de estabelecimentos, nomes empresariais, dentre outros, trazem conjunto de signos os quais também integra a marca. Ao passo que a marca é o signo que identifica um serviço ou produto; já o nome empresarial tem característica de identificar o empresário; o título de estabelecimento tem a característica de identificar o local onde são exercidas as atividades; o nome de domínio identifica o endereço eletrônico utilizado na internet.

A marca serve como um rótulo, uma forma de batismo, para que possa se fazer representada, sem a supressão de sua individualidade. (SCHMIDT, 2013, p.20)

A guerra de marketing será uma guerra de marcas, uma competição de domínio de marca. Os negócios e os investidores reconhecerão as marcas como os mais valiosos ativos da empresa. Este é um conceito crítico é uma visão de como se desenvolver, fortalecer, defender e gerenciar o negócio. Será mais importante dominar mercados do que possuir fábricas, e a única forma de dominar mercados é possuir marcas dominantes.

O poder dos nomes das marcas não se restringe aos mercados consumidores. [...] o conhecimento da marca frequentemente é o ponto-chave na consideração de um comprador industrial. Aliás, mesmo depois de análises, muitas decisões de compras no mercado industrial são lances de um jogo de cara ou coroa. O fator preponderante fica sendo, então, o que a marca significa para o comprador. (AAKER, 1998, p.01) 
Desta forma, conforme a concorrência vai criando uma gama de opções as empresas passaram a buscar formas de estabelecer uma ligação emociona com seus clientes e potencias clientes, tornando- para eles insubstituíveis, visando estabelecer ligações duradouras.

Apenas uma marca forte pode se destacar em um mercado impregnado de tantas opções. Devendo a marca ter a característica de apaixonar seus consumidores, fazendo com que eles confiem e acreditem e se identifiquem com sua superioridade.

Assim, o modo como a marca é percebida, afetará diretamente em suas possibilidades de sucesso ou insucesso, não importando se o bem ou produto é fruto de uma pequena empresa ou "start-up", ou ainda de uma grande companhia. (WHEELER, 2012, p.12)

Temos que a marca passa a ser a assinatura do fabricante em relação ao seu produto, um selo de autenticidade, é como se fosse um rosto, um símbolo que individual, ao passo que terceiros apenas podem utilizá-los como uma máscara.

É verdade que existem hipóteses em que a marca não tem tanta importância, como por exemplo, verduras, frutas e legumes, visto que há uma grande variação de qualidade pelas diferenças climáticas, solo, adubação e até mesmo pragas. Devidas essas grandes variações, em regra, os consumidores realizam inspeção unitária em cada produto para verificar a qualidade de cada qual. Neste ponto a relevância da marca para estes casos acaba perdendo sua força.

Contudo, o mesmo não ocorre com os produtos manufaturados, uma vez que existe pouca ou nenhuma variação nos produtos ou serviços produzidos. Aqui, a marca desempenha uma grande importância no fator de identificação, fazendo com que a inspeção unitária seja dispensada total ou parcialmente, fazendo com que a decisão a ser tomada pelo consumidor seja adotada conforme suas experiências pessoais ou informações sobre o produto. (SCHMIDT, 2013, p.60)

O que chamamos de competition é o cenário competitivo propriamente dito, no qual as decisões estratégicas são baseadas. Já os fatores imagem de marca e brand positioning são considerados como resultados alcançados (brand effects). Vamos então detalha-los.

Competition: é o ambiente o qual se trabalha; os concorrentes, as oportunidades, as ameaças, que se apresentam e servem de parâmetros para a focalização da própria marca dentro da competição na busca de uma posição diferenciada.

Imagem de marca: o que a marca representa na mento do consumidor. A imagem de marca é uma destilação dos componentes de produto, linguísticos e psicológicos. Entretanto, os componentes podem ser afetados pelo ambiente competitivo e por fatores organizacionais, e podem apresentar um caráter de fluidez, levando o valor patrimonial da marca (brand equity) a oscilar. 
Posicionamento da marca (brand positioning): como a marca se posiciona através da implantação de um benefício-chave, tanto no mercado quanto na mente do comprador. A percepção que o público tem da marca é expresso através de um léxico exclusivo, e define sua singularidade. Isso é possível graças a um esforço de comunicação de marketing, que infiltra a marca na lembrança (recall) do mercado. Segundo Al Ries, a marca deve ser dona de uma categoria, isto é, de uma posição exclusiva na mente. (TAVARES, 2003, p.67)

Complementa Almeida, que sobre marca, devemos ter uma compreensão muito além do que apenas um símbolo, nome, ou conjunto deles, mas deve-se ter um percepção que ela reflete uma síntese das ações mercadológicas que emergem a satisfação de desejos ou necessidades específicas do mercado consumidor. Em seguida, é de se ressaltar que a marca ganha maior sentido econômico quando adquire significado exclusivo e se sobressai na mente do maior número possível de clientes. (2010, p.23)

Kotler, entende que as marcas possuem seis níveis de significados, um distinto do doutro, sendo que eles são relacionados aos atributos, benefícios, valores, cultura, personalidade, e usuário do produto. Para ilustrar seu pensamento, traz como exemplo a marca de veículos Mercedes, que representa velocidade, durabilidade, desempenho, prestígio, preço seletivo, cultura alemã e público alvo. Nesta ótica, muitas vezes os consumidores são levados ao desejo pelo consumo para fazer parte de um grupo que tenha valores que lhe tragam identificação. (1999, p.393)

A marca é o somatório do bom e do ruim, do feio e do que não faz parte da estratégia [...] As marcas absorvem conteúdo, imagens, sensações efêmeras. Tornam-se conceitos psicológicos na mente do público, onde podem permanecer para sempre. Como tal, não se pode controla-las por completo. No máximo, é possível orientá-las e influenciá-las. (BEDBURY, 2002, p.37)

Schmidt ensina que marca é um bem incorpóreo que não se confunde com o produto material, sobre o qual se encontra estampada. A marca é um símbolo que identifica o produto ou serviço. Narra que a marca continuará pertencendo ao seu titular, que caso deseje, poderá, utilizá-la noutros produtos e serviços que porventura vier desenvolver. (2013, p.73)

Com essa estratégia, a empresa procura estender o uso de marcas de sucesso para lançar novos produtos ou para modificar determinadas características de produto já existente, por meio de versões com tamanhos, modelos e sabores diferentes. A extensão da marca é uma alternativa que se apresenta ao grande investimento, elevado risco e longo tempo necessário para o desenvolvimento e maturação de novas marcas.

[...] Os investimentos exigidos, sempre de grande monta, devem ser canalizados para identificação do conceito de marca, o desenvolvimento e proteção da marca nominal, a criação da embalagem e o programa de comunicação, em que a publicidade é maciça é obrigatória para divulgar a marca e sustentá-la durante os primeiros anos de sua existência. Para estabelecer um vínculo entre o consumidor e 
a marca, esforços promocionais devem garantir, aos consumidores potenciais, que os benefícios da marca são permanentes e duradouros. (PINHO, 1996, p.25)

Não é tarefa fácil fazer com que um signo comum se transforme numa marca apreciada, exige-se muitos esforços publicitários para consolidar a imagem como marca no mercado de consumo. Por este motivo, após todos os grandes esforços, quando o objetivo é atingido, a marca deve ser protegida pela lei.

Aqueles que conseguem se sobressair tem todos os méritos para auferir com exclusividade todos os benefícios de seus esforços e investimentos. (SCHMIDT,2013, p.133)

Hiller, (2012), ensina que ao falar de marcas temos também que pensar em branding, que o conceitua como uma postura empresária, ou filosofia de gestão que põe a marca no centro de todas as decisões da empresa.

\footnotetext{
As marcas se expressam por meio do nome que apresentam, do logotipo, da forma e do design dos produtos que encarnam, da embalagem e do rótulo, da cor, do slogan, do jingle, da personalidade, do personagem que representa, de um mascote, além de outros recursos e do contexto organizacional, envolvendo os funcionários e os parceiros e suas relações como meio social. (PEREZ, 2004, p.47)
}

Vale destacar que branding, é responsável por comunicar tudo que a marca deseja pregar. Cita como exemplos, a cor dos veículos da empresa, a cor, modelo forma dos uniformes, ou seja tudo que identifica a empresa. Verifica-se que o branding, coloca-se como tendência em comunicação, sendo decorrente de evolução do marketing e publicidade, assim como dos sistemas de identidades visuais corporativos, ao passo que a marca dever ser percebida como um ente vivo, que pode nascer, se desenvolver, amadurecer, renovar-se, podendo permanecer por diversas gerações.

Tão quanto as pessoas, as marcas têm um passado, presente e futuro, desenvolvem relacionamentos tendo sua própria identidade. (MOREIRA, 2009, p. 39)

\section{A INVASÃO SORRATEIRA DA MARCA}

A jornalista canadense Naomi Klein (2004), conta que nos anos 70 as marcas das roupas costumavam ficar escondidas, discretamente inseridas na face interna dos colarinhos. Narra que na primeira metade do século XX, pequenos emblemas de grifes apareciam estampados nos trajes esportivos, mas restringiam-se aos esportes praticados comumente por pessoas com muitas posses financeiras, como o golfe e tênis. 
Com o passar dos anos o mundo da moda se rebelou, fazendo com que o cavaleiro da Polo de Ralph Lauren e o crocodilo de Izod Lacoste saísse do campo de golfe e invadisse as ruas, arrastando seus logotipos definitivamente para o lado de fora das camisetas.

A marca estampada no seio da camiseta tinha a mesma função das etiquetas que marcam preço nos produtos, pois, através da leitura do signo estampado na peça de vestuário, era possível identificar a quantia dispensada pelo usuário para adquirir aquela vestimenta, com a referida distinção.

É certo que o processo de inflação das marcas ainda está em andamento, posto que as marcas cada vez mais buscam ampliar o espaço ocupado nos objetos, entendendo-se que dentre as marcas, nenhuma é mais inchada que a marca Tommy Hilfiger, que foi a primeira grife de roupas a transformar seus adeptos que são fiéis em bonecos Tommy ambulantes e falantes de tamanho natural, sendo estes mumificados em mundos criados totalmente tomados pela referida.

Já nos anos 90, grifes como Nike, Polo, Tommy Hilfger, sentiam-se preparadas para levar suas marcas a um patamar superior. Deixaram de aplicar suas marcas apenas nos produtos, mas passaram a se apresentar à cultura externa, patrocinando eventos sociais, culturais e educacionais.

Desta forma, utilizavam as técnicas do branding para cobiçosamente implantar ideias e iconografia cultural, não sendo apenas uma questão de agregar valores aos produtos comercializados pelas marcas.

Desta forma entendiam que a cultura era quem deveria agregar valor aos seus produtos.

As marcas passaram a usar estratégias muito bem elaboradas para invadir sorrateiramente as mentes dos consumidores, assim, deixaram de realizar os simples patrocínios aos eventos, partindo a estar presente nas artes, cinema, revistas, esportes escolas, etc, assim, faziam que suas logos ocupassem posição central em todos os locais onde estavam presentes, neste ponto, suas presenças deixavam de ter características meramente publicitárias ou uma mera associação oportuna, mas passavam a ser a atração principal.

Um produto de luxo é um conjunto: um objeto (produto ou serviço), mais um conjunto de representações: imagens, conceitos, sensações, que são associados a ele pelo consumidor e, portanto, que o consumidor compra com o objeto e pelos quais está disposto a pagar um preço superior ao que aceitaria pagar por um objeto ou um serviço de características funcionais equivalentes, mas sem essas representações associadas" (ROUX, 2005, p. 127) 
Conforme o pensamento de Kotler, os produtos de moda têm ciclo de vida médio, sendo aceita ou popularizada pelos consumidores durante um período de tempo, descendo lentamente, sendo este lapso de tempo compreendido em regra em cada três meses, ou seja, a cada estação climática.

Há na moda também aquilo que é conhecido como modismo, sendo produtos que entram rapidamente no mercado, sendo aceito com grande entusiasmo, atingindo seu augem em pouquíssimo tempo, entretanto, também declina-se com a mesma velocidade.

O modismo tem pouco tempo de duração e também tem característica de atrair um grupo limitado de seguidores, visto que em regra são norteados pela criação de personalidades famosas, atores, modelos, atletas, músicos, que usam suas aparições na mídia usando ou divulgando acessórios e roupas diferentes daqueles que comumente se vê no mercado, induzindo assim, os consumidores que têm empatia com a personalidade buscar tais adereços para criar uma identificação. (Kotler, 1999, p.225)

Assim, as intensão passou do branding, é empurrar a cultura hospedeira para segundo plano, fazendo com que as marcas sejam o centro, não se anseia patrocinar, impulsionar ou alavancar a cultura, mas anseia-se ser a própria cultura.

O processo de transformação da cultura foi possível diante da ausência de políticas públicas, bem como através das privatizações. Verificou-se o encolhimento dos investimentos governamentais em escolas e museus, deixando estes com ampla necessidade de recuperar seus déficits e se recuperar, buscando parcerias com empresas privadas.

A princípio, aparentemente todos teriam grandes ganhos com a chegadas dos investimentos, escolas e museus se recuperariam e as marcas seriam expostas, uma vez que eram as patrocinadoras. (KLEIN, 2004, p.33)

Com o passar dos anos, os técnicos do marketing e publicidade foram cada vez mais criando estratégias, mecanismos e possibilidades que fizessem com que suas marcas, produtos e serviços caíssem no gosto do consumidor.

Sendo que diuturnamente suas investidas invadem as mentes dos consumidores de forma sutilmente delicada para que não haja rejeição ou sejam criada preferência pela cultura originária daquela sociedade onde as ofensivas de marketing são apresentadas.

\section{A CULTURA DA MARCA OU BRAND CULTURE.}


Antes de abordarmos a cultura da marca, há necessidade de que façamos uma breve pausa para trazer alguns conceitos a respeito do termo cultura que auxiliarão a compreensão e dimensão do conceito.

Para isso, nos apoiaremos no livro Ensaios sobre o conceito de cultura de Zygmunt Bauman.

Ao fazer a leitura do referido texto, podemos perceber que o autor trata a cultura como algo que liberta de opressores e alienações. Podemos perceber que há grande dificuldade na formulação de conceitos, visto que há diante do autor uma infinidade de possibilidades de interpretações a respeito do tema.

O primeiro capítulo do livro, vislumbra três formas de conceituação da cultura; a) como conceito hierárquico; b) como conceito diferencial e c) como conceito genérico.

No primeiro apontamento, entende a cultura como conceito hierárquico, sendo a cultura um instrumento que diferencia um ideal humano, um esforço consciente, fervoroso e prolongado para se atingir tal ideal. (2012, p.93).

Temos em sequência o apontamento que entende a cultura como conceito diferencial, sendo empregado para explicar as diferenças visíveis entre as comunidades de pessoas (temporária, ecológica ou socialmente discriminada). (2012, p.103).

Por fim temos o apontamento que entende a cultura como conceito genérico, que visa apontar os aspectos em comum entre os homens distinguindo-os de tudo mais. (2012, p.131).

Destaque-se que a Declaração Universal sobre a Diversidade Cultural da Organização das Nações Unidas para a Educação, a Ciência e a Cultura - UNESCO, em seu primeiro artigo diz:

Artigo 1 - A diversidade cultural, patrimônio comum da humanidade.

A cultura adquire formas diversas através do tempo e do espaço. Essa diversidade se manifesta na originalidade e na pluralidade de identidades que caracterizam os grupos e as sociedades que compõem a humanidade. Fonte de intercâmbios, de inovação e de criatividade, a diversidade cultural é, para o gênero humano, tão necessária como a diversidade biológica para a natureza. Nesse sentido, constitui o patrimônio comum da humanidade e deve ser reconhecida e consolidada em beneficio das gerações presentes e futuras.

Percebemos que o capitalismo tem circulado através da cultura das mais diversificadas formas.

Para circular pela cultura o capitalismo tem usado com recorrência a publicidade que cada vez mais tem se mostrado como muito mais que um simples artefato de comunicação 
discreto ou um instrumento para vender produtos. A publicidade tem se tornado um sistema social e cultural. Assim, o "branding", recebe a vestimenta de infraestrutura de sentimentos, tornando-se um ambiente mais amplo e alargado, sustentando, legitimando e autorizando os intercâmbios culturais e econômicos dos circuitos capitalistas. (WEISER, 2013, p.169)

$\mathrm{O}$ branding cultural aplica-se particularmente às categorias nas quais as pessoas tendem a valorizar produtos como meio de auto-expressão, como, por exemplo, vestuário, decoração, beleza, lazer, entretenimento, automóveis, alimentos e bebidas. (HOLT, 2004, p. 21).

Podemos perceber que a cultura da marca traz em seu seio a junção das conceituações trazidas por Bauman, diante do fato da marca construir uma relação autentica, afetiva com os consumidores, trazendo com ela uma diversidade de memórias, emoções, experiências e narrativas pessoais.

Neste ponto verificamos que através das marcas, as práticas e expressões culturais podem ser validadas, não apenas como uma simples estratégia mercadológica, mas em espaços culturais onde os indivíduos podem se sentir seguros, autênticos, individuais e importantes.

Assim, a publicidade usa as marcas como plataformas de alegorias para trazem consigo ideologias, sentimento de pertencimento e empoderamento. (WEISER, 2013, p.171).

\footnotetext{
Elas não se baseiam apenas em benefícios, personalidades, ou emoções; mas também no esforço de alertar para ideias pré-concebidas por parte dos consumidores, o famoso "think outside of the box". Isto leva à procura de desejos latentes na sociedade, algo fora da margem da sociedade.

[...]Deve ter a flexibilidade necessária para se afastar e aproximar do consumidor e da cultura que o envolve. [...]Transformar uma marca num ícone propicia um grande valor de identidade, isto porque ela passa a responder a ansiedades e desejos coletivos; que servem de referência no desenvolvimento de uma identidade. Estas ansiedades e desejos são partilhados por uma nação. A comunicação destas marcas procurará dramatizar uma história que resolve com eficácia as ansiedades do consumidor. [...]o próprio consumidor necessita dessa exaltação de sentidos. (PIMENTA, 2012, p.40)
}

Holt explica que os consumidores passam a comprar produtos para vivenciar histórias que lhes foram contadas, assim o produto passa a ser um condutor pelo qual as histórias transmitidas pela marca podem fluir.

O momento o qual o consumidor passa a ansiar a vivência da história que lhe foi contada pela marca, passam a seguir uma marca e por vezes desenvolvem uma comunidade que gira em torno da marca. 
Neste ponto percebemos que a cultura da marca tem potencial de aliciar e induzir os consumidores a ser unirem de modo a desenvolver e ampliar o mito criado pela marca através das interações em sua comunidade.

Conclui dizendo que o valor econômico da marca é baseado no fluxo dos ganhos esperados, provocados pela lealdade dos consumidores em preferir comprar seus produtos e serviços e não de seus concorrentes. ( 2004, p. 105)

As marcas, quando muito e entre outras coisas, são pacotes de significados, alguns robustos, alguns delicados, alguns dos quais estão prontos para dialogar com um ou mais segmentos e atribuir-lhes uma compreensão não apenas do que faz o produto, mas daquilo que ele representa, como pode ser usado, para quem ele pode representar alguma coisa e qual seu lugar em um contexto mais amplo, comercial e cultural (esses valores não são funções que o produto executa; são valores que criam valores). (McCracken, 2011, p. 205)

Neste ponto podemos observar que as marcas podem vir a funcionar como ativistas culturais, criando estímulos aos consumidores para que estes passem a pensar de modo diferente a respeito de si mesmos. As marcas podem fazer com que o consumidor comece a aspirar algo que nunca pensou ser antes possível para si e na sua vida. Ela consegue identificar e perceber os anseios da identidade que constam num corpo social, por este fato, para a marca, é importante estar em harmonia com o contexto histórico do momento, potencializando deste modo o valor da identidade criada por cada mito. (OLIVEIRA, 2012, p. 21)

\footnotetext{
A ideia básica é que, se a empresa conseguir convencer essas pessoas a adotar a marca, configurando-a como um vírus para que seja mais fácil falar a seu respeito, elas, por serem influentes, comunicarão rapidamente o seu interesse pela marca a outros, por intermédio das suas redes sociais, à semelhança da disseminação de um vírus.” (HOLT, 2004,p. 44)
}

Podemos perceber que as marcas passam a integrar, ampliar, modificar, estruturar a cultura dos consumidores passeando pelas três conceituações trazidas por Bauman, tendo capacidade para alterar a identidade dos consumidores através de diversas estratégias que visam dar ao consumidor sentimento de pertencimento, dentre outros sentimentos, que os influenciarão à consumir dado produto ou serviço.

\section{ATAQUE AOS CONSUIDORES}

O grande poder das marcas que vai muito além da mera identificação de produtos ou serviços, mas tem a possibilidade de afetar a cultura dos consumidores, conduzindo-os ao consumo diante da necessidade de pertencimento. 
Conforme foi demonstrado acima, a ausência de políticas públicas culturais, assim como as frequentes privatizações dos órgãos estatais, faz com que a cultura hospedeira seja empurrada para segundo plano fazendo com que resplandeça o brilho da marca, tendo-se como objetivo a tomada de lugar.

Para que fique visível tal ataque, necessitamos ter em mente os três conceitos trazidos por Bauman, cultura; a) como conceito hierárquico; b) como conceito diferencial e c) como conceito genérico.

Observe que ao passo que a marca tem como principal escopo tomar o lugar da cultura hospedeira, ela atinge frontalmente os três conceitos acima, pois pode tomar o lugar de hierárquico quando dá às elites certas marcas de difícil acesso diante do grande valor financeiro para sua aquisição; diferencial, pois tira de certa comunidade sua peculiaridade, aquilo que a distinguia das demais comunidades; e genérico, quando pode homogeneizar todos os homens, cerceando-lhes o poder da diversidade cultural que é natural ao homem.

A Enciclopédia Intercom de Comunicação, através dos conceitos de imperialismo cultural e imposição cultural, demonstra que é percebido que há grande pressão estrangeira através dos meios de comunicação impondo a prevalência da cultura dominante, criando a submissão e alienação do hospedeiro.

Assim, dada cultura é sobreposta à outra de modo forçado, não há restrição no interior de uma nação entre grupos sociais díspares, podendo atuar quando uma nação subjuga outra através de poderio militar ou através das relações econômicas, sendo imposto novo padrão de comportamento.

Deste modo há a criação de diversos prejuízos de grande gravidade que serão percebido no curso dos anos, afetando e influenciando a formação identitária do povo hospedeiro. (2010, p.659 - 661)

Tendo a cultura da marca tamanho potencial ofensivo em relação à cultura local, deve-se criar sobre ela, mecanismos que sejam capazes de impedir ou reduzir os impactos negativos sobre os consumidores.

Basta que façamos a leitura da Declaração Universal sobre a Diversidade Cultural UNESCO, para perceber que os direitos culturais são parte integrante dos direitos humanos, que são universais, indissociáveis e interdependentes, e a defesa da diversidade cultural é um imperativo ético, inseparável do respeito à dignidade humana, implicando no compromisso de respeitar os direitos humanos e as liberdades fundamentais, em particular os direitos das pessoas que pertencem a minorias. 
Em sequência, há necessidade de mencionar que mesmo diante de mudanças econômicas e tecnológicas que são comuns nos dias de hoje, abrindo diversas possibilidades para criação e inovação há imperiosa importância em prestar particular atenção à diversidade da oferta criativa, ao justo reconhecimento dos direitos dos autores e artistas, bem como aos bens e serviços culturais, ao passo que carregam consigo identidade, valores e sentido, não podendo ser consideradas como mercadorias ou bens de consumo como os demais, nos termos do art. $8^{\circ}$ da referida declaração.

É inegável que vivemos num mundo que sofre com os diversificados efeitos da globalização, bem como com os avanços desenfreados das novas tecnologias, entretanto há a imperiosa necessidade de se discutir maneiras para conter os desequilíbrios atualmente produzidos no fluxo e no intercâmbio de bens culturais em todas as escalas.

No art. 11 da Declaração Universal sobre a Diversidade Cultural, temos que é primordial que os governos criem políticas públicas para o desenvolvimento sustentável e promoção da diversidade cultural, não deixando para as forças mercadológicas a preservação e garantia de tais diretos.

É inegável que as marcas através da cultura da marca tem cada vez mais se aproximado dos consumidores ditando os padrões de consumo e vida e consumo. Diante deste acontecimento é necessário que as Cadeiras que estudam o Direito do Consumidor estejam atentas às investidas das marcas, propiciando debates e estudos a respeito do tema, culminando na geração e construção de políticas públicas para o desenvolvimento, ampliação e manutenção da cultura local.

\section{A CULTURA DA MARCA E SESU REFLEXOS NO DIREITO DO CONSUMIDOR}

Como visto na abordagem anterior, o legislador consumerista não apresentou tratamento específico sobre os reflexos da cultura da marca no Código de Defesa do Consumidor, deixando de impor normas expressas de caráter obrigatório que devessem ser respeitadas em prol da proteção máxima do consumidor.

Hoje, dificilmente conseguimos visualizar o mercado de consumo e seu cotidiano sem "marcas". Por certo, poucos irão discordar do fato de que as marcas se transformaram em um dos mais relevantes e perceptíveis elementos do mercado de consumo. 
O consumidor em termos de marca detém um conceito muito limitado, não percebendo a dimensão da interferência da marca na sua vida e na de sua família. Na relação existente entre o consumidor e a marca devem estar presentes o dever de honestidade, que devem ser desenvolvidos pelos agentes que a disponibilizam ao público, de forma que realmente representam aquilo que se propõe, não sendo mais um instrumento para implementar abusividade em face dos consumidores.

A cultura da marca na sociedade detém uma força de dominação muito grande sobre a massa de consumidores. Vive-se atualmente em uma sociedade marcada pelo consumo, onde os indivíduos se cobram na necessidade de consumir. Diante desse contexto os consumidores em sua maioria passaram a ser presas fáceis da cultura das marcas.

Vivemos na plenitude da dominação de fortes marcas, que buscam por todos os meios e técnicas alcançarem seus objetivos mercadológicos. Estudando o tema Dominique Quessada ponderou que:

Serve à ideia de poder, antes de tudo definindo um modo de amar um objeto, ou significando para todos um objeto de amor; e esse objeto de amor não é outro senão o objeto de todo amor (QUESADA, 2003, p. 58).

Para tornarem seus produtos e serviços conhecidos e principalmente consumidos, os fornecedores investem altíssimo na massificação das marcas, pois sabem a dimensão do poder dela. Por outro lado, os publicitários direcionam seus trabalhos considerando as hipóteses de motivação do comportamento dos consumidores, através de estudos psicológicos. Vale apontar os estudos realizados por Christiane Gade (1998, p.85) sobre o tema, chegando a conceituar motivação como "um estado ativado que gera comportamento direcionado".

Os profissionais da comunicação publicitária, infelizmente, ainda utilizam-se de técnicas que são voltadas para as pessoas com baixo nível cultural, baixa autoestima, baixo poder de compreensão, acreditando que estes grupos são alvos mais vulneráveis ao poder das marcas.

Torna-se fácil concluir que o objetivo da cultura de marca é transformar uma opinião particular, de uma empresa sobre seu produto, em opinião pública, de um grupo de consumidores sobre um produto específico, garantindo, assim, sua comercialização.

É inegável o potencial comunicativo das marcas. Daí, inevitável torna-se uma indicação a respeito da semiótica, em razão do envolvimento de signos, códigos, sinais e linguagem com a marca. Lucia Santaella aponta que:

A semiótica estuda os processos de comunicação, pois não há mensagem sem signos e não há comunicação sem mensagem. É por isso que a semiótica nos habilita a 
compreender o potencial comunicativo de todos os tipos de mensagens, nos variados efeitos que estão aptas a produzir no receptor. Esses efeitos vão desde o nível puramente emocional, sensório até os níveis metafóricos e simbólicos. (SANTAELLA, 2002, p.59).

A referida autora em sua obra Semiótica Aplicada, apresenta estudos desenvolvidos por Peirce, tendo em vista que a semiótica integrava a sua arquitetura filosófica. Cuida de evidenciar que nos trabalhos empreendidos por Peirce é possível chegar a conclusão de que existem três elementos formais e universais para tudo que se apresenta perante a mente humana, inclusive, a comunicação e a marca. Aponta a autora:

Num nível de generalização máxima, esses elementos foram chamados de primeiridade, secundidade e terceiridade. A primeiridade aparece em tudo que estiver relacionado com acaso, possibilidade, qualidade, sentimento, originalidade, liberdade, mônada. A secundidade está ligada às ideias de dependência, determinação, dualidade, ação e reação, aqui e agora, conflito, surpresa, dúvida. A terceridade diz respeito à generalidade, continuidade, crescimento, inteligência. A forma mais simples da terceridade, segundo Oeirce, manifesta-se no signo, visto que o signo é um primeiro (algo que se apresenta à mente), ligando um segundo (aquilo que o signo indica, se refere ou representa) a um terceiro (o efeito que o signo irá provocar em um possível intérprete). (SANTAELLA, 2002, p.7).

Dessa forma é possível compreender como a informação se apresenta à mente do consumidor.

Os publicitários há muito tempo já identificaram que a confiança é um fator preponderante para o sucesso de uma marca e sabem que essa confiança muitas vezes não está ligada tão somente ao produto ou serviço, mas também por quem esses produtos são apresentados e oferecidos.

Assim, tanto por questões mercadológicas, quanto no tocante a proteção do consumidor, torna-se patente a necessidade de mudança do atual modelo de comunicação baseado no uso maciço das marcas que é travado entre fornecedor e consumidor. Mas, certamente, essa mudança não irá partir dos fornecedores, que lucram valores absurdos a cada ano. Essa mudança deve partir da própria sociedade como um todo, exigindo políticas que protejam efetivamente o público alvo da cultura de marcas.

\section{CONCLUSÃO}

Visualizar os aspectos da cultura das marcas que norteiam a peculiaridade de um ramo do direito especifico como é o direito do consumidor, habilita o operador do direito a compreender a necessidade de realizar uma releitura das disposições normativas existentes para que o alcance da satisfação dos direitos dos consumidores seja efetiva. 
Assim, percebe-se a partir do quanto aqui apresentado que de nada adianta termos um código de defesa do consumidor de índole protetiva se não tivermos a percepção para perceber as diversas variáveis que podem incidir sobre o consumidor, como no caso em questão, a projeção da cultura das marcas.

Perceber que as relações jurídicas modernas, em especial a de consumo, reclamam por uma superação de institutos tradicionais e destinar as demandas mecanismos específicos que assegurem a efetividade da proteção dos consumidores, tem se apresentado como algo que exige especial atenção do operador do direito.

A Cultura da marca exerce, sem dúvida, uma condução na vida dos consumidores e da própria sociedade, de forma que não é possível se fechar os olhos para essa realidade mercadológica.

No sistema jurídico brasileiro, o Código de Defesa do Consumidor promoveu relevante evolução no que toca a proteção do consumidor, mas é preciso avançarmos na concepção de proteção efetiva, principalmente quando é possível perceber a força que a cultura das marcas exerce no mercado de consumo, ditando hábitos, posturas e ações dos consumidores.

A cultura da marca pode se apresentar, também, como extremamente negativa se desvinculada de valores e princípios.

Destaque efetivo foi dado a possibilidade de verificar o alcance e a dimensão da cultura das marcas no mercado do consumo. De forma que a abordagem aqui apresentada evidencia a preocupação do sistema protetivo em atender o comando constitucional de determinação de proteção e defesa do consumidor. Dessa forma, é nítido que não podemos fechar os olhos para a cultura da marca no mercado de consumo.

\section{REFERÊNCIAS}

AAKER, David A. Marcas: Brand Equity - gerenciando o valor da marca; tradução André Andrade. São Paulo: Negócio Editora, 1998.

ALMEIDA, Carla Aparecida de Sousa. Construção e gestão de marcas próprias no grande varejo supermercadista brasileiro: um estudo de caso. Pontifícia Universidade Católica Administração. São Paulo. 2010. 
BAUMAN, Zygmunt. Ensaios sobre o conceito de cultura. Tradução de Carlos Alberto Medeiros. Rio de Janeiro: Zahar, 2012.

BEDBURY, S. O novo mundo das marcas: 8 princípios para sua marca conquistar a liderança. Rio de Janeiro. Campus. 2002.

CYPRIANO, Isabel Maria Manini. Consumidores brasileiros de marcas de luxo : Quem são e quais seus valores. Timburi. Cia do Ebook. 2015. Disponível em: $<$ https://books.google.com.br/books?id=hVuECgAAQBAJ\&pg=PT57\&dq=marcas\&hl=pt-

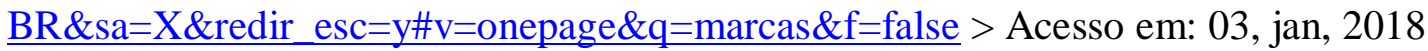

Enciclopédia INTERCOM de comunicação. Sociedade Brasileira de Estudos Interdisciplinares da Comunicação. São Paulo. 2010.

GADE, Christiane. Psicologia do consumidor e da propaganda. São Paulo: Pedagógica e Universitária, 1998.

HILLER, Marcos. Branding: a arte de construir marcas. São Paulo. Trevisan Editora Universitária. 2012

HOLT, D. Como As Marcas Se Tornam Ícones: Os Princípios do Branding Cultural. Boston: Harvard Business School Press, 2004

KLEIN, Nomi. Sem logo. A tirania das marcas em um planeta vendido. Rio de janeiro. Record, 2004. Disponível em:<mediata.org/altercomjor/textos/Naomi_Klein_Sem Logo.pdf> Acesso em: 03, jan, 2018

KOTLER, Philip. Administração de marketing: análise, planejamento, implementação e controle. $5^{\text {a }}$ ed. São Paulo. Altas. 1999.

MCCRACKEN, G. Chief Culture Officer: como a cultura pode determinar o sucesso ou fracasso de uma organização. São Paulo: ALEPH, 2011.

MOREIRA, Ricardo dos Santos. Revisões nos sistemas de identidade visual corporativa de marcas brasileiras: uma análise crítica. Programa de Pós-graduação da Faculdade de Arquitetura e Urbanismo da Universidade de São Paulo. São Paulo. 2009.

OLIVEIRA, Catarina Parkinson de. Branding Cultural e os Media Sociais: A Cultura Indie e a Urban Outfitters. Dissertação para obtenção do Grau de Mestre. Universidade Da Beira Interior. Covilhã. 2012.

PEREZ, C. Signos da marca: expressividade e sensorialidade. São Paulo. Thomson. 2004 PIMENTA, Joana. Branding Cultural e Comunicação de Marcas de Moda. Dissertação para obtenção do Grau de Mestre. Universidade Da Beira Interior. Covilhã e Lisboa. 2012. 
PINHO, J. B. O poder das marcas. São Paulo. Summus. 1996. SCHMIDT, Lélio Denicoli. A distintividade das marcas: secondary meaning, vulgarização e teoria da distância. São Paulo. Saraiva. 2013.

QUESSADA, Dominique. O poder da publicidade na sociedade consumida pelas marcas como a globalização impõem produtos, sonhos e ilusões. São Paulo: Futura. 2003.

ROUX, Elyette; LiPOVETSKY, Gilles. O luxo eterno: da idade do sagrado ao tempo das marcas. Trad. Maria Lúcia Machado. São Paulo: Companhia das Letras, 2005.

SANTAELLA, Lucia. Semiótica aplicada. Thomson Pioneira Learning, 2002.

SCHULTZ. Majken. Esencia de marca. Espanha. LID Editorial Empresarial. 2010

TAVARES, Fred. Gestado da marca: Estatégia e Marketing. Rio de Janeiro. E-papers serviços editoriais. 2003.

UNESCO. Declaração Universal sobre a Diversidade Cultural. Disponível em:< http://unesdoc.unesco.org/images/0012/001271/127160por.pdf>. Acesso em: 03, jan, 2018.

WEISER, Sarah Banet. A crise e seus efeitos: as culturas econômicas da mudança. Org. Manuel Castells, Gustavo Cardoso e João Caraça. Tradução Alexandra Figueiredo, Liliana Pacheco e Túlia Marques. São Paulo. Paz e terra. 2013.

WHEELER Alina. Design de identidade da marca - 3.Ed.: Guia Essencial para Toda a Equipe de Gestão de Marcas. Porto Alegre. Bookman Editora, 2012. 